\title{
An Instructional Approach to Practical Solutions for Plagiarism
}

\author{
Chi Hong Leung*, Simone Chung Ling Cheng \\ Department of Management and Marketing, the Hong Kong Polytechnic University, China
}

Copyright $\bigcirc 2017$ by authors, all rights reserved. Authors agree that this article remains permanently open access under the terms of the Creative Commons Attribution License 4.0 International License

\begin{abstract}
Plagiarism is an academic misconduct commonly found in the educational institutions nowadays. This paper first defines the types of plagiarism and explains the typical reasons for university students to engage in plagiarism. Then, the factors influencing plagiarism are discussed, including the access of materials on the Internet, the social norm of students and the academic policies in universities. This paper suggests an educational approach with the emphasis on the formative assessment to alleviate the problem of plagiarism. Formative assessments are more helpful when students do not need to hide their mistakes and are open about their limitations. This can provide more support for students developing their learning skills, compared with summative assessments in which students do all to suggest competence and conceal ignorance. A survey was performed to collect data about university students' attitudes to the final year project that is a kind of formative assessments. According to the result, the formative assessment is practical for students to understand plagiarism and avoid it. In addition, the learning experience from formative assessments is perceived to be beneficial in completing summative assessments.
\end{abstract}

Keywords Plagiarism, Internet, Social Norm, Academic Strategies, Formative Assessment

\section{Introduction}

Plagiarism defeats the aim of education and the integrity of students. In an education institute, plagiarism is usually a disciplinary offence and there is an increase of the problem recently because of the easy and convenient assess of the materials on the Internet. To explore the concept of academic integrity, there are various kinds of behaviors considered dishonest in higher education. Different forms and methods of academic misconduct were identified by previous research $[40,41,42]$. Plagiarism involves stealing the work of others and presenting it as the own work of the offender. There are various types of plagiarism including copying and pasting, paraphrasing text, and reciting ideas without citing reference. There is inconsistency in defining academic misconduct across the higher education area because academic staff and students may perceive it differently. Students may not clearly understand academic misconduct and do not think it is a serious problem $[14,53]$ and consequently, students may be more likely to plagiarize $[34,49]$. The purposes of this paper are to review factors influencing students' understanding of plagiarism and how plagiarism education can be embedded in the curriculum to alleviate the problem in higher education.

\section{Types of Plagiarism}

Plagiarism is considered dishonest and involves copying or paraphrasing materials from a source but using them as one's own without acknowledging the authors [10, 31, 64]. The problem of plagiarism challenges creativity and originality, personal authorship, and ownership of intellectual work $[6,63]$. There are three types of plagiarism recognized by researchers $[47,65]$.

- Sham paraphrasing correctly cites sources but presents the materials as paraphrased when they are directly quoted.

- Verbatim copies materials from a source without citation and presents it as one's own.

- Purloining submits assignments that are the work of other students with or without their knowledge.

The various appearances of plagiarism make it difficult to define the concept. For example, definitions of plagiarism imply that thoughts and words can be possessed as if they were objects, a notation confusing and misleading for students [35]. Thus, educational practitioners challenged if students understand the concept of plagiarism and use their own words in assignments [11, 59]. Plagiarism is not a simple concept and some students experience an inherent struggle when facing the subject of plagiarism because the institutions may not define clearly what practices are acceptable or not. Such relevant documents may exist but they are not accessible by students [51]. 
There are different reasons for plagiarism [20], including poor academic skills, insufficient understanding of plagiarism, laziness, study pressure, teaching and learning problems and education costs. Studies found that the concept of plagiarism is confusing for students $[5,7,46,47$, 66]. For instance, some students describe plagiarism as copying text with attribution while others do not know the proper procedures to integrate the works and ideas of other authors. Furthermore, some students confuse plagiarism with other kinds of academic misconduct. For example, students consider copying other students' works as collaboration or collusion, instead of plagiarism [7]. Some students even think that assisting other students to complete assignments by copying is not cheating $[18,46]$.

\section{Plagiarism on the Internet}

The rise of information technologies has influenced students who have become digital natives. They are able to download different types of media and this has an unintended consequence that there are a lot of materials that can be cut and pasted easily into their assignments. Plagiarism of online materials is a serious issue in all universities when students are concerned about the acceptable use of the Internet. Without clear direction, most students think that using a few sentences on the Internet without proper citation is not a serious problem [41]. Authorship of online materials is not easy to ascertain because of perception that the Internet materials are in the public domain and these contents do not need acknowledgement $[15,61]$. Thus, students are confused about the usage of online materials for their assignments. The Internet is used as a means of preparation of assignments and students are more likely to engage in plagiarism [60]. On the Internet there are paper mills from which students can obtain and purchase a term paper on a topic [17]. Such paper mills existed before the Internet was popular but the network really makes papers obtainable easily.

The most common type of plagiarism is to copy the published works on the Internet without any acknowledgement or citation. To detect plagiarism is essential to mark and judge works of students who are prohibited from cheating strictly. Plagiarism detection systems are developed into two types. The first type is web-enabled plagiarism detection systems that mainly search plagiarized resources on the World Wide Web. As a well-known system, Turnitin $[13,44]$ has been subscribed by many universities globally. It maintains a huge database that collects content from both previous students' works and the Internet. Similarly, SafeAssign [25] checks the submitted assignments against the Internet, ProQuest database, and institutional assignment archives. In addition, its database contains Global Reference Database that contains essays submitted by students voluntarily to assist in prevention of cross-institutional plagiarism. The second type is stand-alone systems that are installed on computers individually. EVE (The Essay Verification Engine) [22, 32] is a PC application programme searching on the Internet to identify matches between the suspected website and the content of the submitted document. Developed by University of Virginia, WCopyFind [22, 24] detects plagiarism between two essays and the user may modify some operational parameters such as the number of words used for similarity detection.

Besides, other tools like SCAM [43], COPS [57], CHECK [58] and SNITCH [55] utilize various document characteristics like fingerprinting and plagiarism detection methods like fuzzy information retrieval [2]. Plagiarism detection is practically to find out similarity between the submitted document and the content in the database. A document has a several attributes such as the file size, the average line length and the number of punctuation marks per line. These attributes can be counted and processed to form fingerprints of documents for comparison. Files with close fingerprints are considered similar. Another method is to compare content of documents using certain techniques like string tiling, parse tree comparison $[9,26]$ and locating the joint coverage of two files [50,65].

However, there are several simple ways to deceive plagiarism detection systems that examine the textual content of documents. The thesaurus function of a text processor is usually able to change the content of a sentence to avoid being caught by a plagiarism detection system in a convenient manner. The following is an example of a sentence processed by this trick.

Original sentence (from https://en.wikipedia.org/wiki/Computer)

A computer is a device that can be instructed to carry out an arbitrary set of arithmetic or logical operations automatically.

Substituted sentence (manually)

A computer is a machine that can be trained to perform an arbitrary group of math or rational tasks mechanically.

There are also some online article rewriters (like smallseotools.com/article-rewriter and www.freearticlespin ning.com) that convert most of words into synonyms automatically. The following is a substituted sentence generated by smallseotools.com.

$\underline{\text { Substituted sentence (automatically) }}$

A laptop may be a device which will be tutored to hold out associate degree arbitrary set of arithmetic or logical operations mechanically.

This synonym substitution trick is referred to as rogeting that modifies an original text by replacing synonyms to deceive typical plagiarism detection systems like Turnitin. This term was first used by Chris Sadler at Middlesex University [27], who revealed that his students used Roget's Thesaurus in this manner to avoid being caught by the plagiarism detection system. 


\section{Social Norm in the Educational Context}

It is also important to note that plagiarism is influenced by social norms. Students are striving towards behavior consistent with how they perceive behaviors of other members of their social group [28]. Therefore, when the social norms are permissive of plagiarism, students may plagiarize to a greater extent, compared with the norms perceived to be unsupportive [56, 62]. Social learning theory suggests that human behavior is shaped by learning from what other people are doing and their consequences. Engaging in plagiarism is attributed to the strong influence of peers and many university students seek advice of peers to determine what to be accepted behaviors [52]. Once plagiarism is perceived to be acceptable, students are likely to engaging in plagiarism to pursue the required grades and they may feel at a disadvantage if they do not engage in the similar behavior [39]. A study found that perceiving others will cheat and getting away successfully is the strongest and most consistent predictors of cheating behavior [14]. Students engaging in plagiarism may sense that other students are also doing the same. In addition, students who observe others plagiarizing and receiving underserved grades may believe it is not fair to those who do not plagiarize $[1,52]$.

\section{Institutional Expectation and Academic Misconduct Strategies}

Besides confusion and inconsistent concepts of plagiarism, the problem is also complicated by the fact that academic staff may ask students to perform tasks beyond their skill levels [20,47]. Plagiarism may occur when students do not have sufficient capability and, thus, an examination of what are expected by the educational institutions is necessary.

Academic writing is a complicated task that involves many skills but some students may lack them partially and completely. Students may not know how to paraphrase text in their own words to make it markedly different from the original source [4]. Because of time constraints, academic institutions may not offer sufficient tuition in instructing students how to incorporate others' ideas into their own words. Students seem to think that referencing is just a form of etiquette in the academic area and they prioritize gathering sources and citations over development of their own ideas [21]. In addition, students may perceive ownership and authorship differently because of the ease of access facilitated by the advance of technological media.

Students' perceptions of plagiarism are also affected by the preventative strategies of universities $[12,16,19]$. These strategies include administration supporting academic staff enforcing the policy on academic misconduct [33] and conveying expectations within academic misconduct policies to students clearly [48]. There are four kinds of staff development for assisting students to avoid plagiarism [37]. First, teachers should understand students' perspectives and how they learn in various contexts. Second, teachers should have specific skills to provide support to students in need. Third, teachers should be able to reflect on assessment methods and evaluate teaching methods to enhance students' learning experience. Fourth, teachers should focus on understanding their students, instead of changing them to fit the learning context.

The central issue of an academic misconduct policy is to control plagiarism motivated by an absence of ethics [29, 30, 51] and involves process of catching and punishing offenders. To catch plagiarism with detection software like Turnitin is required. If an instance of plagiarism is detected, penalties should match the degree of plagiarism, including caution to expulsion from the school. The plagiarism policy may be available to students but they may not read and understand its content $[45,51]$. Unless these policies are comprehended by all stakeholders, they may not have effect on deterrence [33]. Furthermore, it is found that when academic staff members have greater knowledge of these academic misconduct policies, it is more easily to convince them to engage in classroom preventative measures and process misconduct cases [28].

\section{Instructional Approach to Alleviating Plagiarism}

The purposes of formative assessments are to monitor students' progress and provide continuing feedback to enhance their learning. Particularly, formative assessments can facilitate recognition of students' strengths and weaknesses and help teachers to identify and address their problems promptly. However, formative assessments are usually low stakes that have low or no scores. Typically examples include submission of a research proposal for early feedback and drawing a mind map to represent what are learnt in a lecture. Conversely, the purpose of summative assessments is to evaluate students' learning performance by comparison with some preset standards. They are often high stakes that have high scores. Typical examples include quizzes, exams, and term papers. Students usually commit academic misconducts in these summative assessments like engaging in plagiarism when writing up a term paper.

Just informing students of plagiarism and its consequence is not sufficient to prevent and control it. Students may not care this problem until they really need to do their assignments. One way to alleviate the problem of plagiarism common in a summative assessment is to change it into a number of formative assessments structurally. The following is an example of the design of the formative assessment that can help students to understand plagiarism and avoid it in completing their assignments.

Before students start to do an assignment, a number of lectures on information searching and retrieval techniques 
should be delivered to students. In addition, the guidance on summarizing information from sources should be given. Then, students are asked to perform the literature review on one of topics delivered by the lectures, based on journal papers and conference proceedings. Marks should be awarded for reviewing selected literature and producing a clear report demonstrating students' abilities of using references properly. This should be a totally formative assessment worth, at least, $10 \%$ of the overall grade of the subject to ensure that students can benefit from this experience.

Based on the result of literature review in this short essay, students may build up an essay with their own arguments and logical thinking. In the second formative assessment, students may criticize the contents of the reviewed literature and explain with their own reasons. This assessment involves critical thinking and it is usually not easy to use copy-and-paste method to adopt the materials on the Internet. Students are required to compare and contrast different literature and draw their own conclusion.

In the final formative assessment, students may be asked to develop and create their own thoughts on the topic according to their criticizing results. This assessment puts emphasis on their creativity and self-learning capabilities. In the whole process, a teacher can take into account of the progress of students and understand their strengths and weaknesses to provide prompt feedback to them. Since the assessments are in a step-wise structure and students complete a complicated task with assistance, this makes it less likely to engage in plagiarism.

This is a holistic approach [38] that ensures that students obtain the proper information and abilities in the educational institutions. In addition, the curriculum and assessment design should facilitate skill development in which plagiarism is not encouraged or rewarded. Low stakes formative assessments for learning are focused while high stakes assessments are used cautiously to access how students learn actually. Moreover, academic institutions should have procedures and regulations that not only punish but rehabilitate the students who can avoid plagiarism in the long run. This can make institutions to manage this problem fairly and robustly.

In a high stakes assessment, it is likely that students may do all to suggest competence and conceal ignorance. When this kind of assessment is over-emphasized, students only think of obtaining high marks and shift their focus on the qualification and the final award. It is found that a high stakes assessment encourages behaviors associated with a higher level of plagiarism [47]. A low stakes assessment is more beneficial when students do not need to hide their mistakes and are open about their limitations. This can provide more support for students developing their learning skills, including ways to referencing. Thus, teachers should shift to assessments for supporting students to acquire the appropriate skills and understand how and why to avoid plagiarism.
The formative assessment can improve students' referencing confidence. Students may not understand the concept of plagiarism and do not have required skills to reference and paraphrase appropriately. Thus, teachers should explore practical solutions to tackle such misunderstanding of plagiarism and the lack of referencing skills faced by students. The assessment items should include the opportunity for students to practice the appropriate way of paraphrasing that increases their understanding of plagiarism [8, 36]. These learning tasks should enable students to recognize plagiarism and acknowledge their sources properly.

\section{Results of the Survey on Students' Perceived Attitudes to Formative Assessments}

In this study, 157 business students in a university, after the completion of their final year project, were asked to fill in a survey to collect their attitudes to formative assessments as an education tool avoiding plagiarism. The final year project is a year-long experience designed to provide students with opportunities to consolidate the knowledge and skills they have accumulated in their undergraduate studies. Through this project, they can explore a topic that is of interest to them. The project affords students the chance to investigate this topic in a depth and a breadth that a class project or examination cannot allow. It is also a platform for students to reflect on how their education can be synthesized, distilled, and applied to issues that they care about, including social issues, entrepreneurial ideas, or research questions that they plan on pursuing in the future. To help students make good progress toward the completion of their final year project, several milestones are built in throughout the two semesters. Specifically, they are a) the project proposal, b) the interim report, and c) the final report and individual reflective essay.

Before submission of the project proposal, students should proceed to contact their supervisors to discuss the project scope and expectations. As the nature of each project is different, it is critical that students discuss what they expect to achieve and what they are expected to do in the project with their supervisors at the start of the project. Once the proposal is approved by the supervisor, students can proceed to work on their projects. They should maintain constant communication with their supervisors during this period to update supervisors on their progress and address any issue that arises. Students should submit the interim report in the middle of the project and then the final report at the end of the academic year. In addition to the final report, students are required to write an individual reflective essay discussing their own learning experience.

In this final year project, students take two semesters to complete the final report that is a kind of formative assessment. In the whole process, there is no summative assessment like the quiz and the examination. In addition, 
students have to meet their supervisors regularly for feedback and comments that can help them to further improve and enhance the quality of their research. The purpose of the proposals and interim reports is to help to students to establish a good habit of time management to complete a task in a step-by-step manner. After students had completed the project, they were asked to fill in a survey to compare their learning experience in the project with those in other subjects that mainly focused on summative assessments like examinations and term papers. The survey contained the following questions (see Table 1) and the responses were expressed in the Likert scale from 1 (strongly disagree) to 5 (strongly agree).

Table 1. Survey result

\begin{tabular}{|c|c|}
\hline Questions & $\begin{array}{l}\text { Average } \\
\text { Score }\end{array}$ \\
\hline $\begin{array}{c}\text { The project increases your awareness of what forms } \\
\text { plagiarism. }\end{array}$ & 4.1 \\
\hline $\begin{array}{l}\text { You perceive the learning process in the project as } \\
\text { assisting you in avoiding plagiarism. }\end{array}$ & 4.2 \\
\hline $\begin{array}{l}\text { The project makes you more confident with referencing } \\
\text { and paraphrasing properly. }\end{array}$ & 3.9 \\
\hline There is enough feedback provided in the project. & 3.5 \\
\hline $\begin{array}{l}\text { Feedback from the project helps you to improve } \\
\text { referencing and paraphrasing skills. }\end{array}$ & 3.8 \\
\hline $\begin{array}{l}\text { You learn more about how to avoid plagiarism in the } \\
\text { project. }\end{array}$ & 4.2 \\
\hline $\begin{array}{l}\text { The project makes you more aware of the policies } \\
\text { regarding plagiarism in the university. }\end{array}$ & 4.0 \\
\hline $\begin{array}{l}\text { The learning experience in the project increases your } \\
\text { confidence when doing summative assessment. }\end{array}$ & 4.4 \\
\hline
\end{tabular}

All responses showed positive attitudes to the use of the formative assessment in the final year project. The survey results showed that the formative assessment was helpful for students to understand plagiarism and avoid it. In addition, the learning experience from formative assessments could contribute in doing summative assessments.

\section{Conclusions}

Plagiarism is an important academic problem in the educational institutions. There are several reasons for plagiarism, including poor understanding of plagiarism, poor academic competences, study pressure, improper time management and teaching and learning problems. The problem is becoming more and more severe with the usage of the Internet. Students may simply copy and paste the content from the Internet and use it in their assignments directly. To cope with this problem, electronic plagiarism detection systems are adopted in many universities now. However, such systems mainly rely on comparison of texts and there are ways to avoid being caught by these systems. For instance, the thesaurus function of a text processor replaces the words of copied text and makes it impossible to detect plagiarism with the computer. In addition, social norms of students and academic misconduct strategies of universities have impacts on plagiarism. It is suggested that plagiarism should be avoided through education embedded in the teaching and learning processes.

In summative assessments like term essays, students usually submit the assignment for once at the end of the semester without any comment and feedback when they are preparing the assignment. This practice just requires students to submit the final version of the assignment as an evidence of their efforts completing the task. The intermediate steps of the assignment are not emphasized and this encourages students to engage in plagiarism in which they just copy the source of the plagiarized text and paste it directly in their assignment.

To tackle the problem positively, it is suggested that formative assessments may be used as an education tool to achieve a number of learning objectives regarding plagiarism prevention. There are usually several stages in a formative assessment. Initially, students may be asked to perform the literature review in which they need to study the publications of others. Then, they may comment on the literature review and present their own ideas. In this learning process, teachers should provide comments and feedback to students for correcting their mistakes and suggesting ways for improvement. Finally, students write up the final version for submission.

In this paper a study was performed to collect students' attitudes to formative assessments after their completion of the final year project. The results showed that formative assessments increased students' awareness of what forms plagiarism and assisted them in avoiding plagiarism. This learning experience also increased students' confidence when doing summative assessments. If students are learning-goal oriented, they pay attention to enhancing their academic capabilities and using significant cognitive strategies to tackle problems [23]. Students who cheat are usually more extrinsically motivated and less mastery oriented. Moreover, students with higher self-efficacy are more intrinsic-goal oriented and have higher personal interest in learning, and they are less likely to cheat [54]. In addition, the context of the learning environment (i.e. situational interest) interacts to affect students' decisions to cheat. The likelihood of cheating decreases when students move from high to low performance-oriented classes because competitiveness of the learning environment and extrinsic rewards has impact on cheating [3]

\section{Acknowledgements}

This research was supported by the Departmental Learning and Teaching Enhancement Grant 2015/16 (account code 4.23.xx.88CP) from Department of Management and Marketing at The Hong Kong Polytechnic University. 


\section{REFERENCES}

[1] J. Allen, D. Fuller, M. Luckett. Academic integrity: Behaviors, rates, and attitudes of business students toward cheating, Journal of Marketing Education, Vol. 20, No. 1, 41-52, 1998.

[2] S.M. Alzahrani, N. Salim. Plagiarism detection in Arabic scripts using fuzzy information retrieval. Proceedings of 2008 Student Conference on Research and Development (SCOReD 2008), 26-27 November (pp. 281-285), Johor, Malaysia, 2008 .

[3] E.M. Anderman, C. Midgley. Changes in self-reported academic cheating across the transition from middle school to high school, Contemporary Educational Psychology, Vol. 29, No. 4, 499-517, 2004.

[4] S. Angélil-Carter. Stolen language? Plagiarism in writing. New York, NY: Longman, 2000.

[5] P. Ashworth, P. Bannister, P. Thorne. Guilty in whose eyes? University students' perceptions of cheating and plagiarism in academic work and assessment, Studies in Higher Education, Vol. 22, No. 2, 187-203, 1997.

[6] P. Ashworth, M. Freewood, R. Macdonald. The student lifeworld and the meanings of plagiarism, Journal of Phenomenological Psychology, Vol. 34, No. 2, 257-278, 2003.

[7] R. Barrett, A.L. Cox. 'At least they're learning something': The hazy line between collaboration and collusion, Assessment \& Evaluation in Higher Education, Vol. 30, No. 2, 107-122, 2005.

[8] E. Barry. Can paraphrasing practice help students define plagiarism? College Student Journal, Vol. 40, No. 2, 377 - 384, 2006.

[9] B. Belkhouche, A. Nix, J. Hassell. Plagiarism detection in software designs. Proceedings of the 42nd Annual Southeast Regional Conference, 2-3 April (pp. 207-211), Huntsville, Alabama, USA, 2004.

[10] D.S. Brandt. Techman's techpage: Copyright's (not so) little cousin, plagiarism, Computers in Libraries, Vol. 22, No. 5, $39-41,2002$.

[11] R. Briggs. Shameless! Reconceiving the problem of plagiarism, Australian Universities Review, Vol. 46, No. 1, 19-23, 2003.

[12] J. Carroll, F. Duggan. Institutional change to deter student plagiarism: What seems essential to a holistic approach? Proceedings of the Asia-Pacific Educational Integrity Conference, 2-3 December, University of Newcastle, Australia, 2005.

[13] L. Chao, F. Chen, J. Han, P.S. Yu. GPLAG: Detection of software plagiarism by program dependence graph analysis, Proceedings of the 12th ACM SIGKDD International Conference on Knowledge Discovery and Data Mining, 20-23 August (pp. 872-881), ACM: Philadelphia, PA, USA, 2006.

[14] G.J. Cizek. Detecting and preventing classroom cheating: Promoting integrity in assessment. Thousand Oaks, CA: Dorwin Press, 2003.

[15] A. Colon. Avoid the pitfalls of plagiarism, Writer, Vol. 114, No. 1, 8, 2001
[16] D.F. Crown, M.S. Spiller. Learning from the literature on collegiate cheating: A review of empirical research, Journal of Business Ethics, Vol. 17, No. 6, 683-700, 1998.

[17] N. Cvetkovic. The dark side of the Web: Where to go to buy a paper. In V. Bowman (Ed.), The plagiarism plague: A resource guide and CD-ROM tutorial for educators and librarians (pp. 25-34), New York, NY: Neal Schuman Pub, 2004.

[18] D.I. Del Carlo, G.M. Bodner. Students' perceptions of academic dishonesty in the chemistry classroom laboratory, Journal of Research in Science Teaching, Vol. 41, No. 1, 4764, 2004.

[19] M. Devlin. Policy, preparation and prevention: Proactive minimization of student plagiarism. Journal of Higher Education Policy and Management, Vol. 28, No. 1, 45-58, 2006.

[20] M. Devlin, K. Gray. In their own words: A qualitative study of the reasons Australian university students plagiarize, Higher Education Research \& Development, Vol. 26, No. 2, 181-198. 2007.

[21] D. DeVoss, A.C. Rosati. 'It wasn't me, was it?' Plagiarism and the Web, Computers and Composition, Vol. 19, No. 2, 191203, 2002.

[22] H. Dreher. Automatic Conceptual Analysis for Plagiarism Detection. Journal of Issues in Informing Science and Information Technology, Vol. 4, 601-614, 2007.

[23] C.S. Dweck, E.L. Leggett. A social-cognitive approach to motivation and personality, Psychological Review, Vol. 95, No. 2, 256-273, 1988.

[24] G.J. Edward. Metrics based plagiarism monitoring, Journal of Computing Sciences in Colleges, Vol. 16, No. 3, 191-196, 2001.

[25] M. Ginger, C. Christian. K-gram based software birthmarks, Proceedings of the 2005 ACM symposium on applied computing, 13-17 March (pp. 314-318), ACM: Santa Fe, New Mexico, USA, 2005.

[26] D. Gitchell, N. Tran. Sim: A utility for detecting similarity in computer programs, Proceedings of the 30th SIGCSE Technical Symposium on Computer Science Education, 24-28 March (pp. 266-270), New Orleans, Louisiana, USA, 1999.

[27] Guardian. Rogeting: Why 'sinister buttocks' are creeping into students' essays, 8 August 2014.

[28] S.F. Hard, J.M. Conway, A.C. Moran. Faculty and college student beliefs about the frequency of student academic misconduct, The Journal of Higher Education, Vol. 77, No. 6, 1058-1080, 2006.

[29] L.M. Hinman. Academic integrity and the World Wide Web, ACM SIGCAS Computers and Society, Vol. 32, No. 1, 33-42, 2002.

[30] R.M. Howard. Plagiarisms, authorships, and the academic death penalty, College English, Vol. 57, No. 7, 788-806. 1995.

[31] R.M. Howard. Don't police plagiarism: Just teach! Education Digest, Vol. 67, No. 5, 46-50, 2002.

[32] C. Hung-Chi, W. Jenq-Haur, C. Chih-Yi. Finding Event-Relevant Content from the Web Using a NearDuplicate Detection Approach, Proceedings of the IEEE/ACM International Conference on Web Intelligence, 2-5 November (pp. 291-294), IEEE Computer Society, Washington, DC, USA, 2007 
[33] P.A. Hutton, Understanding student cheating and what educators can do about it, College Teaching, Vol. 54, No. 1, 171-176, 2006.

[34] C.L. Jocoy, D. DiBiase. Plagiarism by adult learners online: A case study in detection and remediation, The International Review of Research in Open and Distance Learning, Vol. 7, No. 1, article 7.1.1, 2006.

[35] A. Johnson, R. Clerehan. A rheme of one's own: How 'original' do we expect students to be, Journal of University Teaching and Learning Practice, Vol. 2, No. 3, 37-47, 2005.

[36] J. Landau, P. Druen, J. Arcuri. Methods for helping students avoid plagiarism, Teaching of Psychology, Vol. 29, No. 2, 112-115, 2002.

[37] B. Leask. Plagiarism, cultural diversity and metaphor Implications for academic staff development, Assessment \& Evaluation in Higher Education, Vol. 31, No. 2, 183-199, 2006.

[38] R. MacDonald, J. Carroll. Plagiarism - A complex issue requiring a holistic institutional approach, Assessment \& Evaluation in Higher Education, Vol. 31, No. 2, 233-245, 2006.

[39] D.L. McCabe, L.K. Trevino. Academic dishonesty: Honor codes and other contextual influences. Journal of Higher Education, Vol. 64, No. 5, 522-538, 1993.

[40] D.L. McCabe, L.K. Trevino. Dishonesty in academic environments, Journal of Higher Education, Vol. 72, No. 1, $29-45,2001$.

[41] D.L. McCabe. Cheating among college and university students: A North American perspective, International Journal for Educational Integrity, Vol. 1, No. 1, 10-11, 2005.

[42] D.L. McCabe, L.K. Trevino, K.D. Butterfield. Cheating in academic institutions: A decade of research, Ethics \& Behavior, Vol. 11, No. 3, 219-232, 2001.

[43] S. Narayanan, G. Hector. Building a scalable and accurate copy detection mechanism, Proceedings of the first ACM international conference on Digital libraries, 20-23 March (pp. 160-168), ACM: Bethesda, Maryland, United States, 2006.

[44] C.J. Neill, G. Shanmuganathan. A Web-enabled plagiarism detection tool, IT Professional, Vol. 6, No. 5, 19-23, 2004.

[45] K. O'Regan. Policing - or, at least, policying — Plagiarism at one Australian university. Journal of University Teaching and Learning Practice, Vol. 3, No. 2, 113-132, 2006.

[46] A. Parameswaran, P. Devi. Student plagiarism and faculty responsibility in undergraduate engineering labs, Higher Education Research \& Development, Vol. 25, No. 3, 263-276, 2006.

[47] C. Park. In other (people's) words: Plagiarism by university students - Literature and lessons. Assessment \& Evaluation in Higher Education, Vol. 28, No. 5, 471-488, 2003.

[48] M.R. Phillips, V. Horton. Cybercheating: Has morality evaporated in business education? International Journal of Educational Management, Vol. 14, No. 4, 150-155, 2000.

[49] J. Pickard. Staff and student attitudes to plagiarism at University College Northampton, Assessment \& Evaluation in Higher Education, Vol. 31, No. 2, 215-232, 2006.
[50] L. Prechelt, G. Malpohl, M. Philippsen. Finding plagiarisms among a set of programs with JPlag, Journal of Universal Computer Science, Vol. 8, No. 11, 1016-1038, 2008.

[51] M. Price. Beyond "gotcha!": Situating plagiarism in policy and pedagogy, College Composition and Communication, Vol. 54, No. 1, 88-115, 2002.

[52] D.A. Rettinger, Y. Kramer. Situational and personal causes of student cheating, Research in Higher Education, Vol. 50, No. 3, 293-313, 2009.

[53] D. Roberts, W. Rabinowitz. An investigation of student perceptions of cheating in academic situations, Review of Higher Education, Vol. 15, No. 2, 179-190, 1992.

[54] G. Schraw, L. Olafson, F. Kuch, T. Lehman, B.S. Lehman, M.T. McCrudden. Interests and academic cheating. In E. Anderman, \& T. Murdock (Eds.), The psychology of academic cheating (pp. 59-85), Amsterdam: Academic Press, 2007.

[55] N. Sebastian, P.W. Thomas. SNITCH: A software tool for detecting cut and paste plagiarism, Proceedings of Special Interest Group on Computer Science Education, 1-5 March (pp.51-55), ACM: Houston, Texas, USA, 2006.

[56] J. Selingo. The cheating culture. Prism Magazine, Vol. 14, No. 1, 2004. Retrieved from http://www.prism-magazine.org/sept04/feature_cheating.htm

[57] B. Sergey. Copy detection mechanisms for digital documents, Proceedings of the 1995 ACM international conference, 2 May (pp. 398-409), ACM: New York, USA, 1995.

[58] A. Si, H.V. Leong, R.W.H. Lau. CHECK: A document plagiarism detection system, Proceedings of the 2007 ACM symposium on Applied computing, 1 April (pp. 70-77), ACM: San Jose, California, United States, 1997.

[59] C. Thompson. Discourses on plagiarism: To discipline and punish or to teach and learn, 2002. Retrieved from http://195.130.87.21:8080/dspace/bitstream/123456789/291/1 /Thompson-Discourses\%20of\%20plagiarism.pdf

[60] J. Underwood, A. Szabo. Academic offences and e-learning: Individual propensities in cheating, British Journal of Educational Technology, Vol. 34, No. 4, 467-477, 2003.

[61] P. Whiteneck. What to do with a thought thief. Community College Week, Vol. 14, No. 24, 4-7, 2002.

[62] B.E. Whitley Jr. Factors associated with cheating among college students, Research in Higher Education, Vol. 39, No. 3, 235-274. 1998 .

[63] B.E. Whitley, P. Keith-Spiegel. Academic dishonesty: An educator's guide. Hillsdale, NJ: Lawrence Erlbaum, 2002.

[64] S. Wilhoit. Helping students avoid plagiarism, College Lecturing, Vol. 42, No. 4, 161-164, 1994.

[65] M.J. Wise. YAP3: improved detection of similarities in computer program and other texts, Proceeding of SIGCSE'96 Technical Symposium, 15-17 February (pp. 130-134), ACM: New York, USA, 2006.

[66] S. Yeo. First-year university science and engineering students' understanding of plagiarism, Higher Education Research \& Development, Vol. 26, No. 2, 199-216, 2007. 